\section{PHOTOGRAPHY IN AGRICULTURAL RESEARCH}

$\mathrm{O}$ $\mathrm{N}$ April 29, the Association for Scientific Photography held a meeting at Caxton Hall, London, to discuss "Photography as a Tool in Agricultural Research". Papers were read by Dr. E. M. Crook and Mr. V. Stansfield, of Rothamsted Experimental Station, and by Mr. J. C. Hawkins and Mr. R. H. Broome, of the National Institute of Agricultural Engineering, Askham Bryan, and illustrated by lantern slides and cine films.

The word 'tool' was included in the title in order to emphasize the fact that the centre of interest should be no radically new departure in the use of photographic materials in agricultural research, but simply the day-to-day use of well-known and well-tested techniques such as can be depended upon to yield results with a minimum of trouble and incidental research.

A large proportion of the photographic work of both inștitutes, as indeed is true of all photography applied to science, arises as a result of the need for an adequate means of preserving a detailed and easily comprehended record of very complex situations and phenomena. A single photograph will often record experimental results more adequately than several pages of written notes; in addition, it often preserves for future reference effects which were quite unnoticed at the time the experiment was made. Similar considerations apply to the use of photographs for passing on instructions for assembling or adjusting an agricultural implement or recognizing a certain plant disease. The photographic record, being objective, is also a valuable means of establishing beyond dispute the results of tests such as the Institute of Agricultural Engineering continually carries out on articles submitted by manufacturers.

Many records are enhanced in value, and in dramatic effect, by the use of colour. This is especially true of the recording of plant disease symptoms and the results of manurial trials such as make up a considerable proportion of the work at Rothamsted. On the other hand, where relative positions and the demonstration of movements are important, as at Askham Bryan, colour does not present any particular advantage. Other special techniques include the use of infra-red plates to record satisfactorily the lesions in the streak diseases of potato.

Recording does not, of course, cease with macroscopic objects, so far as Rothamsted is concerned. Illustrations were shown of records of the life-cycles of two soil organisms, crystals of plant viruses and of the lesions caused by such viruses, all of which involve photomicrography. The electron microscope now available at Rothamsted allows these records to be extended right down to the actual particles of virus and particles of clay (Fig. 1) at magnifications of $20-30$ thousand diameters.

At the other end of the scale comes the use of aerial photographs (Fig. 2) for observing crops, the first of which were taken in 1925 by the R.A.F., at the request of Rothamsted. As is well known, aerial photographs show up differences com-

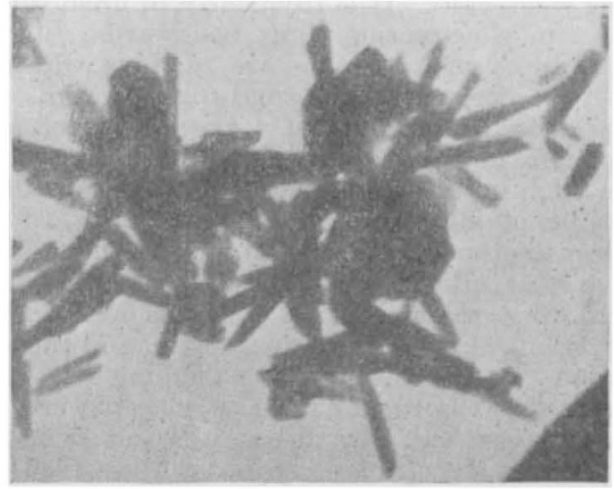

Fig. 1. The clay mineral, halioysite. ElectronMICROGRAPH TAKEN AT ROTHAMSTED BY DR. F. M. L. SHEFFIELD. $\times 20,000$.

pletely invisible from the ground, and make possible the recording on a single plate of such differences in crops covering many acres.

Most of this 'still' recording work (except electron micrographs and aerial photographs) is done with modern small cameras; the Leitz Leica using $35 \mathrm{~mm}$. film at Rothamsted, or the Zeiss Super Tkonta, giving $2 \frac{1}{4}$ in. $\times 3 \frac{1}{4}$ in. pictures at Askham Bryan. The former can be easily adapted for photomicrography by means of the 'Ibso' attachment, or by extension tubes and the sliding copy device, and both are in use at Rothamsted, as well as the Leitz 'Makam' camera, all of which are attached directly to a standard microscope.

Cinematography also finds a valuable place in this work. At Rothamsted, a comprehensive study has been made of the formation of cell inclusions in plants infected with virus, and several stills from this film were shown at the meeting. This film was made using exposures twelve times as long as normal, and when run at the normal rate gives a speeded-up effect which makes possible the detection of many movements which occur too slowly to be seen by direct observation. At Askham Bryan even more use is made of cinematography, partly for educational work and partly for studying the performance of machines. It has been found that the use of the 'aerial' shot is of great advantage in illustrating the movement of farm machinery; a special portable tower $20 \mathrm{ft}$. high, mounted on a lorry, is used for

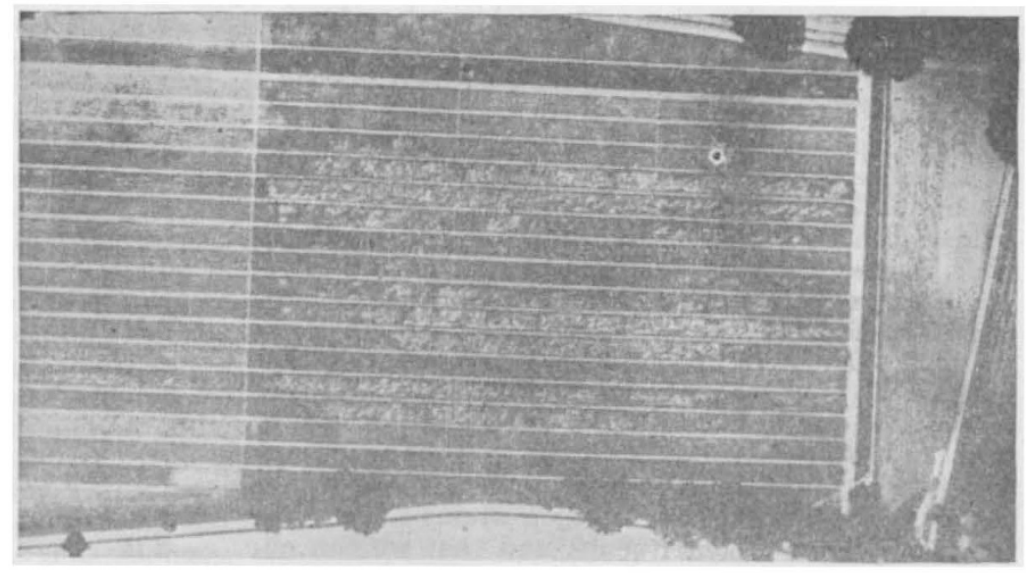

Fig. 2. BROADBAJK FIFId, ROTHAMSTED. AERIAL PHOTOGRAPH BY R.A.F. IN 1930. THE DIFFERENTIY MANURED STRIPS, SOME WITH MUCH LODGING, STAND OUT PLAINIY. THE DIFFERENCES BETWEEN FALLOW (RIGHT) AND OROP (LEIT) DURING THE PRECEDING
YEAR OAN AISO BE SEEA. 
making such shots. It is frequently of great advantage to run slow-motion films backwards. In such circumstances many points are obvious which can scarcely be noticed in a normal forward run. Illustrative excerpts of films of a potato digger and a disk-plough in action were shown.

The 'high light' of the afternoon was a speeded-up film of ploughing, made at Askham Bryan, to teach the best methods of laying out and ploughing a field so that idle running of plough and tractor is reduced to a minimum. A suitable field on Teesside overlooked by a eliff was the site, and the whole operation of setting out and ploughing was photographed from the top of the cliff, one picture being taken every second. In this way it was possible to compress two days ploughing into a film which could be shown at the normal rate in 40 minutes. The effect, as well as being very instructive, was amusing, as the tractor and plough appeared to move at about 50 m.p.h.

In addition to these direct methods of employing photography, two uses of the photographic emulsion at Rothamsted were touched upon: spectrographic analysis, both qualitative and quantitative, and $\mathrm{X}$-ray diffraction work on clay minerals, in both of which the sensitive emulsion is used as a recording medium. Standard equipment is used for both-a Hilger medium quartz spectrograph and a Cambridge cylindrical powder camera of $28 \mathrm{~mm}$. radius.

The spectrographic work includes the analysis of soils and plants for such elements as calcium, potassium, sodium, manganese and magnesium, and the detection and estimation of trace elements such as copper and boron and, in one or two recent instances, zinc, lead and chromium in toxic soils. Elements of the first group are estimated from lines excited in the Lundegärdh burner, and calibration curves are plotted with the ratio of line density to background density as ordinate and logarithms of the concentration as abscissæ. Elements of the second group are estimated from lines excited in the carbon and copper are, using suitable internal standards; for example, tin for boron, the intensity of the tin line at $2496 \mathrm{~A}$. being compared with the boron line at $2498 \mathrm{~A}$.

The X-ray work is indispensable for the identification of minerals found in soil colloids and clays. The electron microscope will undoubtedly help greatly in this work, but as yet, insufficient data are available for the best use to be made of its possibilities. As a general rule, powder diagrams. of clay minerals are poor because of the large scattering near the central beam, and aggregate diagrams must be used instead. However, the newer technique of replacing the air in the camera by hydrogen so cuts down the scattering as to make the former more valuable, particularly when obtained from an aggregate.

In the short discussion following the papers, Prof. Yule Bogue raised the question of the limitation of the electron microscope for the examination of biological material by the necessity for working in a vacuum. Dr. Crook, replying, pointed out that the vacuum is only one of the limitations, since the electron-scattering power of the oxygen atoms of the water which constitutes so large a proportion of living material is much greater than the scattering power of the carbon and nitrogen atoms which are the chief 'organic' constituents, and that we can at best hope for an image rather like a radiograph if it becomes possible to use wet material (say, by a freezing technique).

\section{NUCLEAR ENERGY-LEVELS}

THE following is a summary of a paper by $P$. Comparat* which came into the writer's hands by an unorthodox but topical procedure. Printed at Lyons in 1942 , it was brought from France by an officer of the Free French forces in 1943. It then found its way into the hands of Prof. D. Saurat, of the French Department of King's College, London, who presented it to the College library. The work described therein was carried out at the Faculty of Sciences, Lyons, initially under the direction of Prof. J. Thibaud. The research occupied a period of four years, full time being devoted to the problem.

Introduction. The first demonstration of the transmutation of nitrogen by rapid neutrons was that of Feather in 1932, using a cloud expansion chamber. The suggested reaction was

$$
{ }^{12} \mathrm{~N}+n \rightarrow{ }^{4} \mathrm{He}+{ }^{11} \mathrm{~B}+Q,
$$

where $Q$ was negative, thus corresponding to an endoenergetic reaction. Subsequent workers, for example, Chadwick and Goldhaber, showed in 1935 with an ionization chamber and a linear amplifier that exo-energetic disintegration also occurred in this reaction. About the same time, Kurie demonstrated that an alternative reaction occurred in which protons were emitted instead of $\alpha$-particles.

The aim of Comparat's research was to measure the number of disintegrations at various energies of disintegration and to see if the magnitude and distribution of the energy-levels agreed with the current theory. By 1.936 the discord between theory and experiment was considerable; the existing theory,

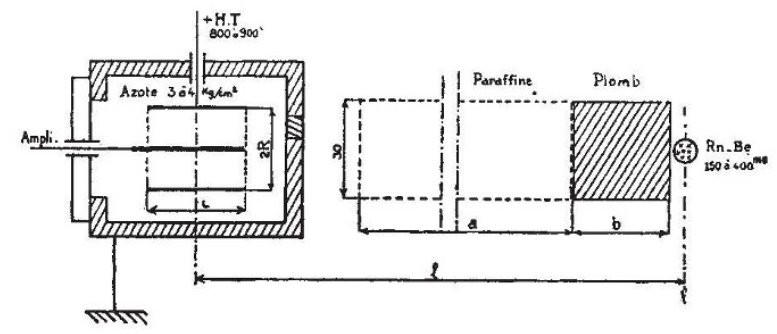

Fig. 1.

based on the two-body concept of the interaction of the incident neutron with the ${ }^{14} \mathrm{~N}$ nucleus, predicted a few nuclear levels of considerable width. On the contrary, experiment showed numerous sharp levels. Again, theory predicted identical values for the diffusion and capture cross-sections of slow neutrons, whereas experiment showed a large ratio.

At about this time, Bohr introduced the concept of nuclear transmutation according to which the incident neutron amalgamates with the entire nucleus to form an intermediate nucleus (in this case ${ }^{15} \mathrm{~N}$ ) of appreciable duration. The intermediate nucleus afterwards disintegrates, for it is in an excited state, with the emission of a heavy particle, often accompanied by $\gamma$-radiation. In the special case of nitrogen bombarded by neutrons and boron bombarded by $\alpha$-particles, the whole process is reversible, thus:

" "Disintegration of Nitrogen by Fast Neutrons; Distribution of the Energy Levels of $N^{15}$ ". By P. Comparat. Pp. 96. (Lyon, 1942.) 